\title{
Surface microrelief obtained by composed target deposition for LC molecules alignment
}

\author{
Yu. Kolomzarov, P. Oleksenko, V. Sorokin, P. Tytarenko, R. Zelinskyy \\ V. Lashkaryov Institute of Semiconductor Physics, NAS of Ukraine \\ 41, prospect Nauky, 03028 Kyiv, Ukraine
}

\begin{abstract}
Technology of $\mathrm{SiO}_{\mathrm{x}}$ :In,Sn aligning films deposited by the cathode reactive sputtering (CRS) method is presented. The influence of In, Sn alloy surface concentration in Si cathode target on aligning film properties are investigated by the AFM and optical profilometry methods. The properties of aligning microrelief obtained by CRS method for various In, Sn concentration and by the polyimide rubbing method are compared. It was shown that such aligning microrelief can create defectless and perfect at the microscopic level nematic LC oriented structures.
\end{abstract}

Keywords: reactive cathode sputtering, aligning films, nematic liquid crystal, microrelief, AFM.

Manuscript received 07.08.06; accepted for publication 23.10.06.

\section{Introduction}

In present LCD production a lot of techniques for creation of the planar or tilted homogeneous alignment of liquid crystal molecules (e.g., vacuum thermal deposition or electron beam evaporation of oxides, rubbing of the polymer films, photoalignment, plasma treatment and others [1-6]) are used. But these technologies have many imperfections. For example, rubbing of polymer coatings generate dust particles and high static voltage, mechanical and electrical damages of the active matrix elements (thin film diodes or TFT), requires to use high temperatures (up to $280^{\circ} \mathrm{C}$ ) and long-term (several hours) processes for imidization. Several years ago, in the Institute of Semiconductor Physics, NAS of Ukraine the essentially new vacuum method for creation of aligning layers was proposed $[7,8]$. This method is based on the reactive cathode sputtering of silicon target in glow discharge plasma in argon and oxygen atmosphere [9].

In this work, the investigation results of the new original technology for creation of the aligned LC structures based on cathode reactive sputtering (CRS) were presented.

\section{Experimental setup}

\subsection{Vacuum deposition setup}

The setup for cathode reactive deposition of aligning layers is based on standard vacuum setup VUP-5. A special water-cooled cathode was mounted at the top part of the bell-jar. As a cathode target we used silicon wafers that were soldered by indium and tin (5\%) alloy on the cathode plane. Silicon wafers have square shape through holes. The size and arrangement of holes give possibility to realise three different surface concentration of indium and tin (5\%) alloy in silicon: 5, 10 and $20 \%$. The total area of the target was $60 \mathrm{~cm}^{2}$, the area of a sputtered region was $20 \mathrm{~cm}^{2}$. The sputtering of the target was carried out in atmosphere of the argon-oxygen mixture. Substrates were mounted in the special holder enabling to change the slope angle between the normal to the target plane and substrates within the range from 10 up to $45^{\circ}$. Special system allows scanning the substrates in the course of deposition of aligning layer. The cathode voltage was varied from 1 to $5 \mathrm{kV}$; DC density was varied from 2 to $5 \mathrm{~mA} / \mathrm{cm}^{2}$. Deposition of aligning layers was performed using the gas mixture pressure within the range from $6 \cdot 10^{-2}$ to $8 \cdot 10^{-3}$ Torr. For capillary or vacuum filling, we used industrial Merck LC ZLI-3145 with the addition C15.

\subsection{Construction of testing LC cells}

To investigate homogeneous and twist alignment quality by the polarization microscopy method, we used liquid crystal cells. For preparation of these cells, we used float glass (Glaverbel, thickness $1.1 \mathrm{~mm}$ ) substrates with sizes $20 \times 30 \mathrm{~mm}$. First type samples was spin-coated with AD9103 (fabricated in NIIOPIK, Moscow) at 2,000 rpm and then annealed at $280{ }^{\circ} \mathrm{C}$ for 1.5 hours. The alignment was created using the standard rubbing process. 
Alignment in second type samples was created by the method of Si target reactive cathode sputtering. After that, on one half of both types of substrates the BEN-50 glue (a mixture of polyvinylbytiral solution in ethyl alcohol and epoxy-novolacs block copolymer solution in acetone) was applied, and spacers with the diameter of $6 \mu \mathrm{m}$ were sprayed onto another half of substrates.

The substrates of the first and second types were assembled for creation of homogeneous and twist alignment. After curing of glue (pressure $4 \mathrm{~atm}$, temperature $180^{\circ} \mathrm{C}$, time 1 hour), cells were filled with various types of LC materials. Cells of both types with twist alignment were filled with the mixture of LC ZLI3145 and the addition C15 (capillary in the air and vacuum). Cells of both types with homogeneous alignment were filled with LC E7 (capillary in the air and vacuum).

\subsection{Microrelief investigation}

To study the microrelief, the optical profilometry method was used $[10,11]$. This method has resolution close to $1 \mathrm{~nm}$ for investigation of the surface topography and along $\mathrm{X}$ - and $\mathrm{Y}$-axis has resolution approximately $0.7 \mu \mathrm{m}$. Each image was formed using 64,000 analyzed points. Aligning microrelief was studied by AFM, too. The scanning areas were $1 \times 1 \mu \mathrm{m}$ and $0.5 \times 0.5 \mu \mathrm{m}$ for detailed section analysis.

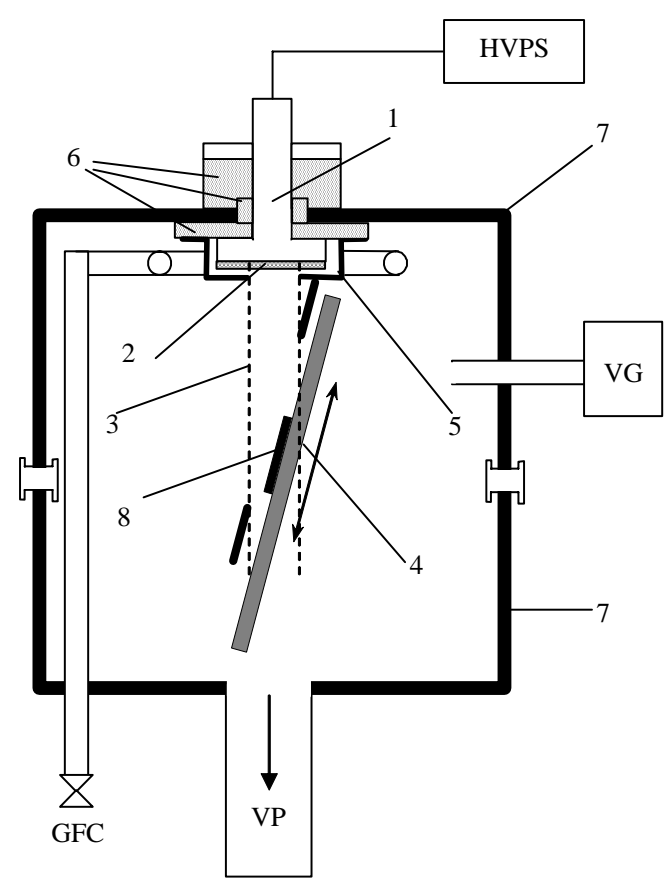

Fig. 1. Vacuum setup for cathode reactive deposition of aligning layers: 1 - cathode, 2 - silicon-indium target, 3 plasma column, 4 - substrate holder, 5 - shield, 6 - insulating tubes, 7 - bell-jar, 8 - substrate, VP - vacuum pumps, GFC gas flow controller, VG - vacuum gauge, HVPS - high voltage power supply.

\section{Results and discussion}

\subsection{Technological parameters of $\mathrm{SiO}_{x}: \mathrm{In}$, Sn thin film deposition}

The previous investigation showed some imperfections of $\mathrm{SiO}_{\mathrm{x}}$ aligning layers, such as different align properties dependent from a previous layer (opened glass, ITO electrode), degradation under the influence of organic glues evaporation and necessity to heat glued substrates in the course of vacuum filling with LC mixture. To exclude this imperfection, the cathode targets of silicon and indium were produced. The performed study showed that the orientation quality depends on a great amount of technological parameters during aligning layer deposition (the cathode voltage, discharge current density, gas or gaseous mixture pressure, oxygen concentration in an operating mixture, angle and time of deposition, etc.).

Our analysis showed that technological regimes for $\mathrm{SiO}_{\mathrm{x}}$ aligning layer deposition are suitable for deposition of $\mathrm{SiO}_{\mathrm{x}}: \mathrm{In}$, Sn aligning layers, which provide the high quality of nematic LC alignment. Nomograph for determination of the technological parameters of aligning layers deposition is presented in [12].

\subsection{Results of polarization microscopy investigation}

The investigation of LC twist and homogeneous structures obtained using the substrates with deposited from Si:In, Sn target aligning layers demonstrate the same defectless and perfect alignment at the microscopic level. This result is similar to that described in [12]. Alignment is practically independent from the previous layers (opened glass, ITO electrode or $\mathrm{SiO}_{2}$ protected layer). It was confirm by the optical profilometry investigation of $\mathrm{SiO}_{\mathrm{x}}: \mathrm{In}$, Sn aligning layers deposited onto various layers.

\subsection{Results of microrelief investigation by optical profilometry method}

Fig. 2 shows the results of microrelief investigations. Table contains the numerical characteristics of the microrelief: $R_{t}$ means the height of the maximum peak in the investigated area, $R_{a}$ means an arithmetically averaged height of the microrelief in the investigated area, $R_{q}$ means a root-mean-square high of the microrelief in the investigated area.

Figs $2 \mathrm{a}$ and $\mathrm{b}$ demonstrate the surface microrelief of $\mathrm{SiO}_{\mathrm{x}}: \mathrm{In}$, Sn aligning layers deposited on glass from target with the concentrations of In, Sn alloy 10 and $20 \%$, respectively. The numerical characteristics of the microrelief are essentially different.

Figs 2c and d demonstrate the aligning microrelief deposited onto the ITO layer that was deposited on the glass substrate by the CRS of In $+5 \%$ Sn target in the oxygen (12\%) and argon gas mixture. The initial ITO microrelief had a lot of peaks [12]. It is a typical microrelief for ITO layer deposited by the CRS method 

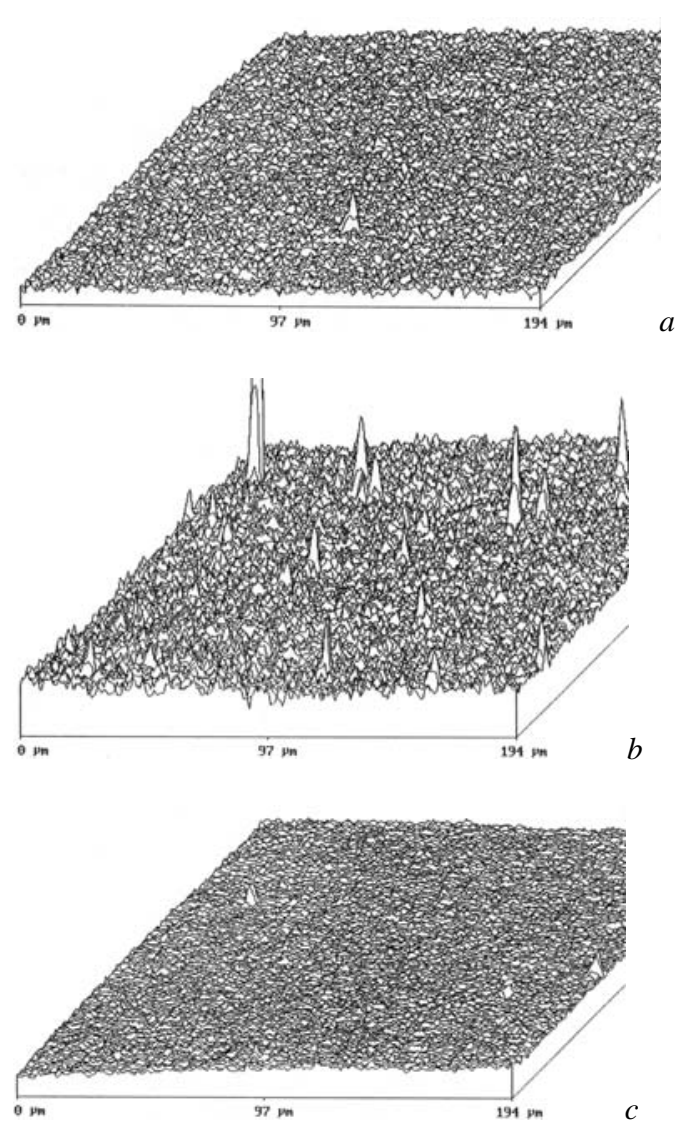
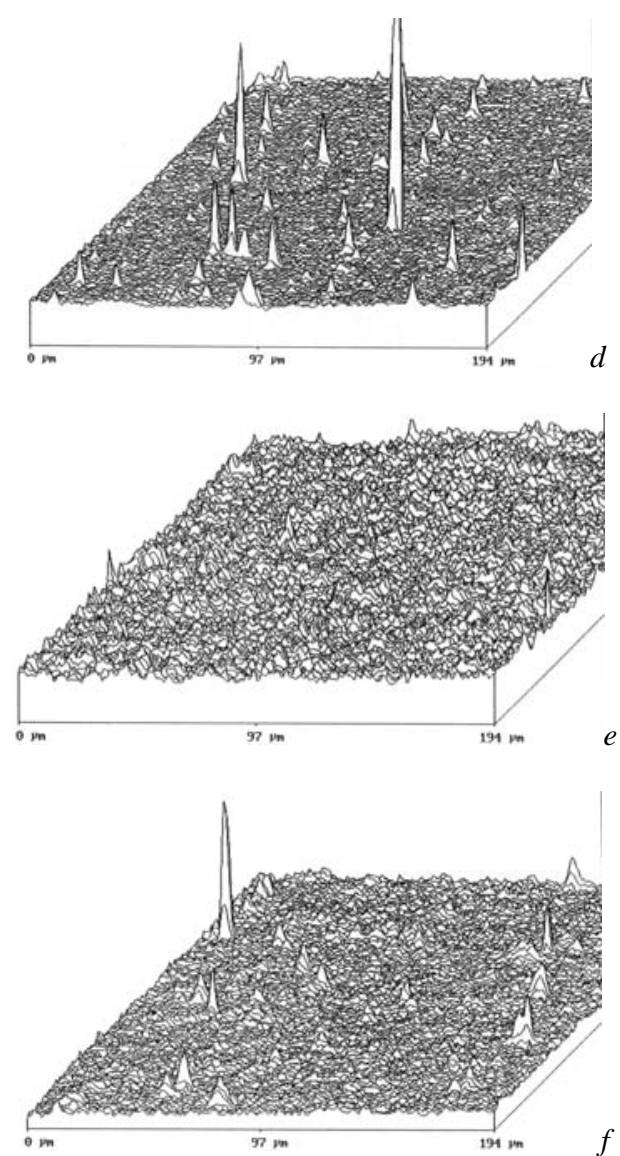

Fig. 2. Images of the microrelief inherent to In, Sn concentration in Si target for deposition of $\mathrm{SiO}_{\mathrm{x}}$ : In, Sn alignment layers.

in comparison with the magnetron RF sputtered ITO layer that is smoother. After deposition of $\mathrm{SiO}_{\mathrm{x}}: \mathrm{In}, \mathrm{Sn}$ aligning layer from target with the concentrations of In, Sn alloy 10 and $20 \%$, respectively, the numerical characteristics of the microrelief are sufficiently different, too (see Table).

Table. Numerical characteristics of the microrelief.

\begin{tabular}{|c|c|c|c|c|}
\hline $\begin{array}{l}\text { Layers before deposition } \\
\text { of aligning layer } \rightarrow \\
\text { deposited layer }\end{array}$ & Figure & $R_{t}, \mathrm{~nm}$ & $\begin{array}{l}R_{a}, \\
\mathrm{~nm}\end{array}$ & $\begin{array}{l}R_{q}, \\
\mathrm{~nm}\end{array}$ \\
\hline $\begin{array}{l}\text { Glass } \rightarrow \text { CRS of } \mathrm{SiO}_{\mathrm{x}} \text { : In, } \\
\text { Sn (10\% In, Sn in target) }\end{array}$ & $2 a$ & 20.3 & 1.0 & 1.3 \\
\hline $\begin{array}{l}\text { Glass } \rightarrow \text { CRS of } \mathrm{SiO}_{\mathrm{x}}: \text { In, } \\
\text { Sn (20\% In, Sn in target) }\end{array}$ & $2 b$ & 127.6 & 1.8 & 3.0 \\
\hline $\begin{array}{l}\text { Glass+ITO } \rightarrow \text { CRS of } \\
\mathrm{SiO}_{\mathrm{x}}: \mathrm{In}, \mathrm{Sn}(10 \% \mathrm{In}, \mathrm{Sn} \text { in } \\
\text { target })\end{array}$ & $2 c$ & 23.2 & 0.8 & 1.1 \\
\hline $\begin{array}{l}\text { Glass }+ \text { ITO } \rightarrow \text { CRS of } \\
\text { SiO }_{x}: \text { In, Sn }(20 \% \text { In, Sn in } \\
\text { target })\end{array}$ & $2 d$ & 173.8 & 1.6 & 2.1 \\
\hline $\begin{array}{l}\text { Glass+ITO+SiO }{ }_{2} \rightarrow \mathrm{CRS} \\
\text { of } \mathrm{SiO}_{\mathrm{x}}: \mathrm{In}, \mathrm{Sn}(10 \% \mathrm{In}, \\
\text { Sn in target) }\end{array}$ & $2 \mathrm{e}$ & 36.8 & 1.6 & 2.1 \\
\hline $\begin{array}{l}\text { Glass }+\mathrm{ITO}+\mathrm{SiO}_{2} \rightarrow \mathrm{CRS} \\
\text { of } \mathrm{SiO}_{\mathrm{x}}: \mathrm{In}, \mathrm{Sn}(20 \% \mathrm{In}, \\
\mathrm{Sn} \text { in target })\end{array}$ & $2 f$ & 85.5 & 1.0 & 1.7 \\
\hline
\end{tabular}

Figs 2e and $\mathrm{f}$ demonstrates the surface microrelief of $\mathrm{SiO}_{\mathrm{x}}$ :In, $\mathrm{Sn}$ aligning layer deposited on $\mathrm{SiO}_{2}$ layer that was deposited by the pyrolytic decomposition method on a glass substrate with ITO layer. The initial $\mathrm{SiO}_{2}$ microrelief possesses a developed surface. It is a typical microrelief for ITO layer covered with the pyrolytic $\mathrm{SiO}_{2}$ layer [12]. After deposition of $\mathrm{SiO}_{\mathrm{x}}$ alignment film by the CRS method, characteristics of the microrelief considerably decreased (see Table). This decrease is a consequence of negative oxygen ion treatment of the surface. The treatment made the surface more smooth. It is possible to observe the presence of valleys parallel to the direction of alignment layer deposition in this image of surface microrelief.

The results of investigations show that the properties of aligned LC layers are practically independent of the previous layers. It confirms investigations of aligned LC layers by the polarization microscopy.

3.4. Results of microrelief investigation by the AFM method

To investigate aligning microrelief topography, the AFM method was used. The aligning layers obtained by rubbing cured polyimide and deposited by the CRS technology from target with $20 \%$ of In, Sn in Si. Topographies of aligning layers created by rubbing 

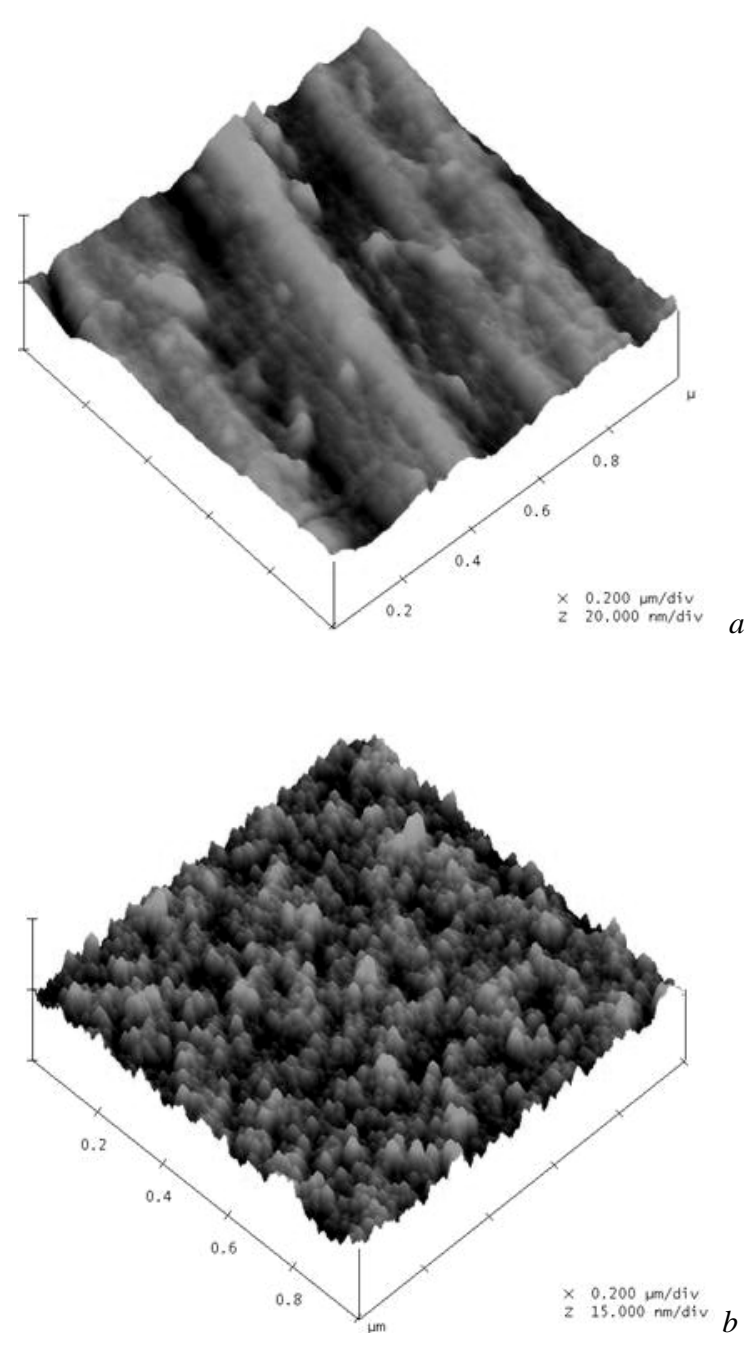

Fig. 3. Topography of aligning layers created by rubbing of cured polyimide (a) and $\mathrm{SiO}_{\mathrm{x}}: \mathrm{In}$, Sn aligning layer deposited from target with concentration of In, Sn alloy $20 \%$ by CRS technology (b).

cured polyimide and $\mathrm{SiO}_{\mathrm{x}}: \mathrm{In}, \mathrm{Sn}$ aligning layer deposited from a target with the concentration of In, Sn alloy $20 \%$ by the CRS technology were shown in Figs 3a and b, respectively.

This results in appearance of defects in aligned LC structures created by rubbed polyimide layers. This result was confirmed by the polarization microscopy investigations of aligned LC structures published in [12]. In contrast to rubbed polyimide, the $\mathrm{SiO}_{\mathrm{x}}$ :In, $\mathrm{Sn}$ aligning layer deposited from target with the concentration of In, Sn alloy $20 \%$ by CRS technology has a defectless microrelief that is able to create a LC aligned structure perfect at the microscopic level [12].

For more detailed analysis of $\mathrm{SiO}_{\mathrm{x}}: \mathrm{In}, \mathrm{Sn}$ aligning microrelief by the AFM, the area with sizes $0.5 \times 0.5 \mu \mathrm{m}$ was scanned more thoroughly. Additionally the microrelief section parallel to the direction of deposition was analyzed. Topography and section analysis of $\mathrm{SiO}_{\mathrm{x}}: \mathrm{In}, \mathrm{Sn}$ aligning layer deposited from $\mathrm{Si}$ target with
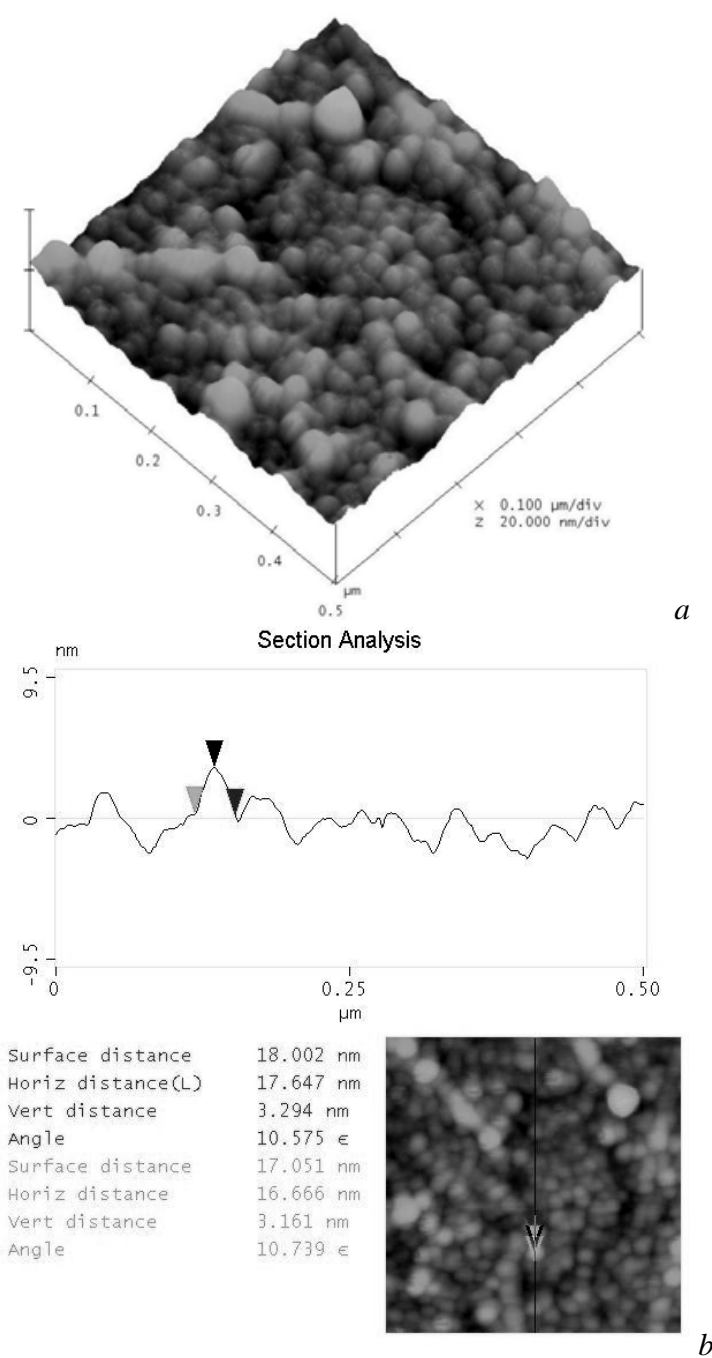

Fig. 4. Topography (a) and section analysis (b) of $\mathrm{SiO}_{\mathrm{x}}: \mathrm{In}, \mathrm{Sn}$ aligning layer deposited from target with the concentration of In, Sn alloy $20 \%$ by CRS technology.

the concentration of In, Sn alloy $20 \%$ by CRS technology was shown in Fig. 4. The amplitude of microrelief is several nanometers that correspond to the measurement by using the optical profilometry method (see Table). The corners of front and rear slopes are approximately 11 degrees. Such geometry parameters explain the uniformity of LC aligned structures and its defectless at the microscopic level.

\section{Conclusions}

It is obvious that the rubbed polyimide layer has a lot of imperfections: dust particles in created channels, some channels is not parallel to common rubbing direction. Investigations of the properties of aligning layers deposited by the CRS from Si target with the concentration of In, Sn alloy $20 \%$ in atmosphere of the $\mathrm{Ar}$ and $\mathrm{O}_{2}$ mixture were shown that this method is applicable for creation of nematic LC molecules

(C) 2006, V. Lashkaryov Institute of Semiconductor Physics, National Academy of Sciences of Ukraine 
alignment in the direction coinciding with the ion bombardment and material deposition. The substrate plane should be oriented at the definite angle to the cathode plane normal. Analysis of LC twist and homogeneous aligned structures by the polarization microscopy demonstrated that the $\mathrm{SiO}_{\mathrm{x}}: \mathrm{In}$, Sn aligning layer deposited from target with concentration of In, Sn alloy $20 \%$ by the CRS technology able to create the defectless LC structures perfect at the microscopic level. The offered method opens a direct way to create ecologically pure high productive technology of LC displays without using the harmful chemical compounds. Investigations by the optical profilometry and AFM methods showed that $\mathrm{SiO}_{\mathrm{x}}$ :In, Sn aligning layers have an island structure with the height up to $3 \mathrm{~nm}$ in comparison with that in organic continuous layers. This island aligning structure is not an insulator and does not produce the voltage drop when the external electric field was applied. It is a very important property for characterization of LC mixtures and gives for researchers the possibility to measure directly electrical conductivity and dielectric constants of LCs in direct current conditions. Moreover, using these aligning layers allows to create new types of LC devices.

\section{References}

1. E.S. Luk'yanchenko, V.A. Kozunov, V.I. Grigos, Orientation of nematic liquid crystals // Uspekhi khimii 54, No 4, p. 214-238 (1985) (in Russian).

2. W.J.A. Ctoosens, Bulk interfacial and anchoring of liquid crystals // Mol. Cryst. Liquid Cryst. 124, No 14, p. 305-319 (1985).

3. Zh. Konyar, Orientation of nematic liquid crystals and their mixtures. Universitetskoye, Minsk, 1986 (in Russian).

4. H. Tabira, T. Inoue, Y. Yahagi, H. Imayama, M. Morimoto, Precision rubbing supported by fine process analysis // J. SID 10, No 4 (2002).
5. D. Fedorenko, E. Ouskova, Yu. Reznikov, V. Reshetnyak, S. Shiyanovskii, O. Frarirescangeli, F. Simoni, Properties of bulk-mediated photoalignment of doped liquid crystal // Mol. Cryst. Liquid Cryst. 359, p. 137-145 (2001).

6. M. Hasegava, Fabrication of freely patterned aligned nematic LC cell by using photoalignment // Proc. 21st Intern. Display Research Conference in conjunction with 8th Intern. Display Workshops, October 16-19, 2001, p. 57-60.

7. Yu. Kolomzarov, P. Oleksenko, V. Sorokin, P. Tytarenko, R. Zelinskyy, Oblique reactive cathode sputtering as a method for creation of orienting liquid crystal microrelief // Proc. 12th Intern. Symposium “Advance Display Technology", Korolyov, Moskow Region, Russia, August 25-28, 2003, p. 150-153.

8. Yu. Kolomzarov, P. Oleksenko, V. Sorokin, P. Tytarenko, R. Zelinskyy, Vacuum method for creation of liquid crystal orienting microrelief // Semiconductor Physics, Quantum Electronics and Optoelectronics 6(4), p. 528-532 (2003).

9. V. Sorokin, N. Kuzmin, P. Oleksenko, Y. Kolomzarov, R. Zelinski, V. Semenist, Investigation of methods for molecular alignment in nematic and smectic liquid crystal displays // Mol. Cryst. Liquid Cryst. 215, p. 137-143 (1992).

10. H. Perrin, P. Sandoz, G. Tribillon, Longitudinally dispersive profilometer // Pure Appl. Opt. A 4, p. 219-228 (1995).

11. H. Perrin, P. Sandoz, G. Tribillon, High resolution profilometry by using phase calculation algorithms for spectroscopic analysis of white light interferograms // J. Mod. Opt. 43, No 4, p. $701-708$ (1996).

12. Yu. Kolomzarov, P. Oleksenko, V. Sorokin, P. Tytarenko, R. Zelinskyy, Peculiar properties of LC orientation by thin inorganic oxide films obtained by glow discharge plasma // Proc. XV Conference on Liquid Crystals, edited by Jozef Zmija, 2004. Proc. SPIE 5565 (Bellingham, WA) p. 359-364. 